
on cation chromatography. Blood was obtained at delivery from 13 normal and 9 insulin-dependent mother-infant pairs. Glycosylation of $\mathrm{Hb}(\mathrm{G}-\mathrm{Hb})$ was compared to fructose standards and expressed as nM fructose equiv. (FE) $/ \mathrm{mg}$ Hb.

\begin{tabular}{|c|c|c|c|c|}
\hline meantSD & & $\begin{array}{l}\text { P1. GIucose } \\
\text { (mg/dl) }\end{array}$ & $\begin{array}{c}\text { Fetal Hb } \\
(8)\end{array}$ & $\begin{array}{c}\mathrm{G}-\mathrm{Hb} \\
\text { (nM } \mathrm{FE} / \mathrm{mg} \mathrm{Hb} \text { ) }\end{array}$ \\
\hline \multirow[t]{2}{*}{ Normal (13): } & Mother & $72 \pm 15$ & -- & $12.6 \pm 3.5$ \\
\hline & Infant & $76 \pm 27$ & $83 \pm 6$ & $7.8 \pm 3.5$ \\
\hline \multirow[t]{2}{*}{ Diabetic(9): } & Mother & $155 \pm 112$ & -- & $15.6 \pm 3.2$ \\
\hline & Infant & $158 \pm 81$ & $90 \pm 2$ & $8.5 \pm 1.8$ \\
\hline
\end{tabular}

Maternal $\mathrm{Hb} \mathrm{AI}_{\mathrm{C}}$ determined by HPLC correlated significantly wit
maternal $\mathrm{nM} \mathrm{FE} / \mathrm{mg} \mathrm{Hb}(\mathrm{p}<0.01)$. Infant $\mathrm{G}-\mathrm{Hb}$ correlated with maternal $\mathrm{G}-\mathrm{Hb}(r=0.63, p<.005)$. Both infant groups were decreased compared to mothers $(p<.001)$. Infant bloods chromatographically separated into " $F$ " pools revealed no differences from whole blood $\mathrm{Hb}$. The decreased glycosylation in fetal blood may relate to decreased fetal red cell survival and/or $\mathrm{Hb} F$ structure. Nevertheless, maternal hyperglycemia results in fetal hyperglycemia which glycosylates fetal hemoglobin.

\section{MORPHOGENESIS AND MALFORMATIONS}

ASSOCTATION OF CONGENITAL TRACHEAL OBSTRUCTION AND 1196 GENITOURINARY ANOMALIES IN THE NEWBORN. P.L.S. Amma Gerald Katzman, Venkatesan Krishnan, Jose Urrutia, Irwin Weinfeld, Sidney Kripke, Malini Satish. (Spon. by M. G. Robinson) Medical College of Ohio, The Toledo Hospital, Dept. of Pediatrics, Toledo, Ohio.

Three infants presented with tracheal obstruction at birth and were later found to have genttourinary anomalies. Infants \#1 and \#2 were siblings of the same sex (male) born a year apart. Infant $\# 1$ died in delivery. Autopsy revealed laryngeal stenosis with a pinpoint opening at the tracheal introitus, renal hypoplasia, malformed penis with protruding foreskin and hypospadias. Infant \#2 failed to breathe at birth. Trials at intubation failed and tracheotomy was performed subsequently with successful ventilation. Bronchoscopy revealed laryngeal stenosis with a pinpoint opening at the tracheal introltus with redundant skin at the nape of the neck, a malformed penis with protruding foreskin and absent meatus, and was anuric. Investigation showed no functioning renal tissue. Autopsy confirmed the above findings and absent ureters, bladder, urethra and prostrate. Karyotyping showed a $46 \mathrm{XY}$ male. Infant \#3 was born to a 37 Yo dlabetic mother. Unsuccessful attempts were made at intubation. Bronchoscopy revealed a tracheal web. She also had cardiac anomalies and intrapelvic genital organs and left kidney. Chromosome analysis showed a $46 \mathrm{XX}$ female. We suggest that there is an association of tracheal obstruction and genitourinary anomalies.

FORAMEN OVALE SIZE AS A MARKER OF TRANS1197 ATRIAL BLOOD FLOW DURINC CARDIAC DEVELOPMENT. Department of Pediatrics, University of lowa, lowa City, Tow

We studied the ratio. of the foramen ovale area to the total atrial septum area in 18 normal hearts and 33 hearts with congenital cardiac anomalies. The congenital defects included tricuspid atresia, 5; pulmonary atresia, 4; secundum atrial septal defect, 9; coarctation of the aorta, 8; and aortic stenosis, 7 .

In the $10 \%$ formalin fixed specimens, the margins of the atrial septum were defined and marked with India ink. The hearts were coded, positioned with the septum flat and photographed with a grid. The areas of the atrial septum and foramen ovale were measured using standard planimetric techniques. A ratio of the foramen ovale to atrial septal area was calculated.

The area of the atrial septum did not differ significantly among the six groups. The foramen ovale/atrial septal ratio in normal hearts was $0.19+.01$ (SEM). The ratios in tricuspid atresia $(0.41+.02)$, puTmonary atresia $(0.38+.02)$, and secundum atria! septal defect $(.37 \pm .01)$ were significantly larger than normal $(p<.05)$ while the ratio in coarctation of the aorta $(0.15 \pm .01)$ and aortic stenosis $(0.11+.01)$ were significantly smaller $(p<.05)$.

These data indicate that foramen ovale size is directly related to the magnitude of trans-atrial blood flow during embryonic and fetal development, and provide support for the role of intracardiac blood flow in cardlac morphogenesis.
REDUCT ION IN OOCYTE NUMBER FOLLOW ING PRENATAL EXPOSURE TO A HIGH GALACTOSE DIET. Y.T. Chen, D. Mattison, L. Feigenbaum, H. Fukui, and J.D. Schulman, NICHD and NE I, NIH, Bethesda, Md.

Even with a galactose (GAL) restricted diet started perinatally galactosemic women frequently manifest primary or secondary amenorrhea with ovarian failure. We postulated that prenatal or early postnatal exposure to excessive GAL and/or its metabolites might be toxic to oocytes or their precursors. Rats received a control or 50\% GAL diet during pregnancy and nursing (day 3 of gestation thru 3-4 wks postnatal), or GAL only while nursing. Oocyte number and follicle type was quantitated as described by Pederson \& Peters using stained 5 u serial sections of the 3-4 wk. infant ovary. Animals exposed to GAL prenatally plus postnatally had marked reduction in mean total oocyte number compared to controls $(2120+410$ S.E.M. vs. $8680+964$, p .0001$)$. This was accounted for almost entirely by a reduction in type I (primary) oocytes $(1380 \pm 336$ vs. $7500 \pm 818$, p <.0001). No significant change was documented in number of preantral or antral follicles. Postnatal GAL caused equally severe growth retardation with or without prenatal GAL (each an $\sim 3 X$ reduction in body, liver, and kidney wt. vs. controls) but postnatal GAL alone produced no reduction in number of total $(8400+581)$ or type I $(7280+363)$ oocytes. In the rat, prenatal exposure to galactose strikingly reduces the number of primary oocytes; the precise timing and mechanism of toxicity now require elucidation. Galactosemic females may acquire ovarian damage in utero if the mother does not receive a galactose-free diet.

DOUBLE OUTLET RIGHT VENTRICLE FOLLOWING CONO-

1199 TRUNCAL CONSTRICTION IN THE CHICK EMBRYO. Edward B. Clark and Clenn C. Rosenquist, Department of Pediatrics, University of Towa, lowa City, lowa and Childrens Hospital National Medical Center, Washington, D.C.

We are studying the effect of a timed teratogenic event on cardiac morphogenesis. A $0.5 \mathrm{~mm}$ loop of 10-0 nylon was placed constricting the midpoint of the conotruncus in stage 24 chick embryos. The embryos were reincubated and harvested between stages 36 and 40 . The embryo hearts were fixed in diastole, microdissected and measured. The study group included 46 experimental, 35 sham operated and 72 control embryos.

In 27 (59\%) experimental embryos, the aorta arose from the right ventricle. In this group the separation of the mitral and aortic valve (MAS) $(0.85+.06 \mathrm{~mm})$ was significantly greater $(p<.05)$ than sham operated and control embryos $(0.34+.09 \mathrm{~mm})$. MAS did not increase with developmental stage. All embryos with double outlet right ventricle had 1 or more ventricular septal defects and 7 (26\%) had aortic arch malformations.

Among 15 embryos with the aorta originating from the left ventricle the MAS $(.50+.05 \mathrm{~mm})$ was not significantly different from controls. All but one embryo in this group had a ventricular septal defect and $6(40 \%)$ had aortic arch malformations. Right ventricular size was similar among experimental, sham operated control embryos.

These data indicate a timed teratogenic insult to the conotruncus can interfere with the assignment of the aorta to the left ventricle resulting in double outlet right ventricle and the persistance of the aortic conus. OXOLINIC ACID ON EMBRYONIC DEVELOPMENT AND MACROMOLECULAR BIOSYNTHESIS. Steven J. Czinn, Howard S. Carr and William T. Speck, Case Western Reserve Untversity, Rainbow Babies and Childrens Hospital, Department of Pediatrics, Cleveland, Ohio

The effect of environmental agents on child health is a subject of considerable interest. Of special concern are the long term effects of such agents and more specifically their carcinogenic and/or teratogenic potential. The present study evaluated the teratogenic potential of three antimicrobial agents which are specific inhibitors of DNA gyrase in prokaryotic cells by evaluating their effect on embryonic development and macromol cular biosynthesis using as a model system the American Sea Urchin and human cells in vitro. Nal and Nov induced dose-dependent abnormalities in embryos at concentrations which preferentially inhtbit DNA synthesis. Thus, concentrations in excess of $100 \mu \mathrm{g} / \mathrm{m} 1$ resulted in abnormal clevage patterns in embryos, developmental arrest at blastulation and a $50 \%$ reduction in DNA synthesis with little or no effect on RNA and protein synthesis. Al1 three agents affected macromolecular biosynthesis in human cell in vitro. Concentrations of these drugs in excess of $333 \mu \mathrm{g} / \mathrm{ml}$ resulted in a $60 \%$ reduction in RNA synthesis, a $30 \%$ reduction in DNA synthesis with little or no effect on protein synthesis. These results provide evidence for DNA gyrase act1vity in eukaryotes and suggest that agents which preferentially inhibit this enzyme are potential teratogens whose use in human populations may be associated with serious long-term sequellae. 